NASA Technical Memorandum 87230

\title{
A Model for the Influence of Pressure on the Bulk Modulus and the Influence of Temperature on the Solidification Pressure for Liquid Lubricants
}

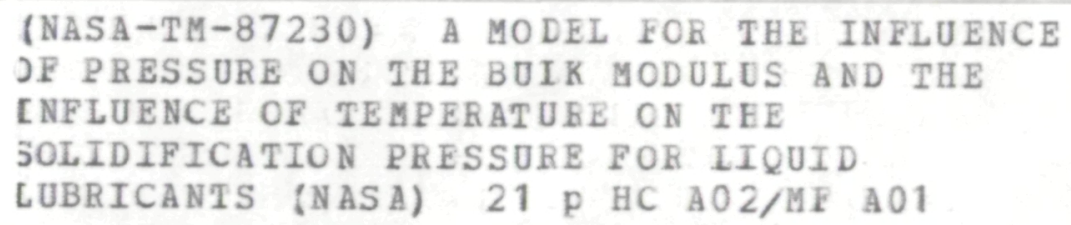

Bo O. Jacobson and Pascal Vinet

Lewis Research Center

Cleveland, Ohio

Prepared for the 1986 ASME/ASLE Tribology Conference

Pittsburgh, Pennsylvania, October 19-22, 1986

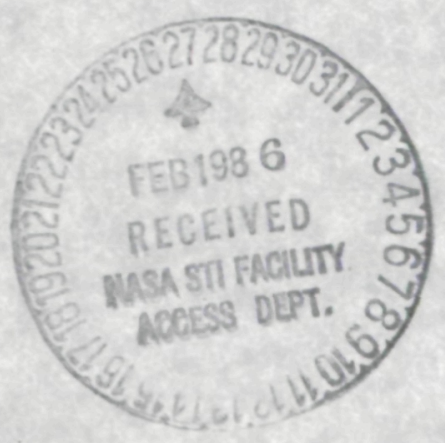




\section{A MODEL FOR THE INFLUENCE OF PRESSURE ON THE BULK MODULUS \\ AND THE INFLUENCE OF TEMPERATURE ON THE \\ SOLIDIFICATION PRESSURE FOR LIQUID LUBRICANTS}

Bo 0. Jacobson* and Pascal Vinet*

National Aeronautics and Space Administration

Lewis Research Center

Cleveland, Ohto 44135

\section{ABSTRACT}

Two pressure chambers, for compression experiments with liquids from zero to $2.2 \mathrm{GPa}$ pressure, are described. The experimentally measured compressions are then compared to theoretical values given by an isothermal model of equation of state recently introduced for solids. The model describes the pressure and bulk modulus as a function of compression for different types of lubricants with a very high accuracy up to the pressure limit of the high pressure chamber used $(2.2 \mathrm{GPa})$.

In addition the influence of temperature on static solidification pressure was found to be a simple function of the thermal expansion of the flutd. NOMENCLATURE

B bulk modulus, $\mathrm{N} / \mathrm{m}^{2}$

$B_{0} \quad$ bulk modulus at zero pressure, $\mathrm{N} / \mathrm{m}^{2}$

m mass, $\mathrm{kg}$

p pressure, $N / m^{2}$

$\mathrm{t}$ temperature, ${ }^{\circ} \mathrm{C}$

$v$ volume, $m^{3}$

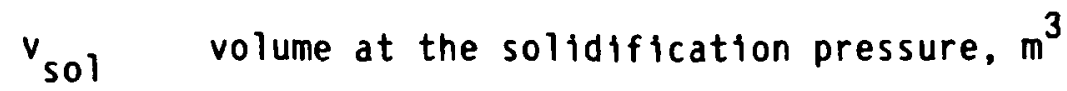

*Visiting Scientist from University of Luleă, Lulea, Sweden.

$\star \star V i s i t i n g$ Scientist from Laboratoire de Technologie des Surfaces, Ecole Centrale de Lyon, B.P. 163, 69131 Ecully Cedex, France. 
$v_{\text {sol, }}$ the volume the lubricant should become if it were decompressed from the solid state down to zero pressure keeping the solid state properties, $\mathrm{m}^{3}$

$x \quad$ parameter in bulk modulus and pressure equation $x_{\text {sol }}\left(v / v_{\text {sol }, 0}\right)^{1 / 3}$

$\mathbf{\alpha}$ coefficient of thermal expansion, ${ }^{\circ} \mathrm{C}^{-1}$

$r \quad \partial T_{L} / \partial p$, shear strength increase with pressure

$\delta$ coeffictent of thermal volume expansion, ${ }^{\circ} \mathrm{C}$

$\rho$ density of lubricant, $\mathrm{kg} / \mathrm{m}^{3}$

$n$ parameter in bulk modulus and pressure equation ${ }^{T} \mathrm{~L}$ shear strength of lubricant, $\mathrm{N} / \mathrm{m}^{2}$

INTRODUCTION

In the calculation of the $011 \mathrm{f} 11 \mathrm{~m}$ thickness in elastohydrodynamic lubrication, the compressibility and the change of lubricant behavior from liquid to solid type, are very important. The compressibility of the lubricant determines the shape and the thickness of the oil film in the central almost parallel part of it. Lubricants with high compressibility give a thinner central oil film than stiff lubricants. If the compressibility is high enough, the minimum film thickness will not appear at the outlet of the elastohydrodynamic contact, but in the center of the contact. There the area of low film thickness will be much larger than the outlet area with low film thickness. Due to the large close contact area and the high pressure in this area, the heating and energy dissipation, if the ofl film fails, is much more severe than it should be if the minimum film thickness were the same, but only occupying the side lobes and outlet part of the contact.

The change of solidification pressure with temperature is also important for the lubricant film thickness but is even more important for the power dissipation in the elastohydrodynamic contact. If the temperature rise is 
high enough that the 011 behaves like a 1iquid, even in the central part of the contact, the friction forces will decrease and become lower than the limiting shear stress of the lubricant. In this paper two test apparatuses are described, one for measurement of the bulk modulus at low pressures and the other for measurement of the compression curves for high pressures up to $2.2 \mathrm{GPa}$ for liquid lubricants. A physical model, built upon consideration of the atomic interaction forces in the lubricants, describes the pressure-compression relationship, for all lubricants tested, using only two parameters. These parameters are the bulk modulus at zero pressure $B_{0}$ and the pressure derivative of the bulk modulus at zero pressure $\left(\partial B_{0} / \partial p\right)_{p=0}$.

The high pressure chamber was also used to measure the change in solidification pressure with a change in temperature.

\section{The High Pressure Chamber}

A detailed description of the high pressure chamber can be found in Ref. 1. Equipped as in Ref. 1, the high pressure chamber can be used to determine the solidification pressure for lubricants by measuring the shear strength of the fluid as a function of pressure. A description of the specially equipped high pressure chamber for high accuracy measurements of the compression of lubricants can be found in Ref. 2 .

A drawing of the apparatus is shown in Fig. 1. As is described in Ref. 2 the pressurized volume between the plungers can be measured very accurately. The maximum error being about $2 \times 10^{-4}$ of the total volume. It is not only possible to measure the compression of the fiuid in the high pressure chamber but also to measure the shear strength of the fluid as a function of the pressure. In these experiments the solidification pressure is said to be the pressure at which the shear strength of the fluid starts to increase linearly with pressure as $\partial \tau_{L} / \partial p=\gamma$. 
The high pressure chamber was used for measurement of the compression of the fluids from 0.4225 to $2.20 \mathrm{GPa}$. At pressures below $0.4225 \mathrm{GPa}$ some of the lubricants with low viscosity at these pressures did leak past the steel seals as the steel seals were not plastically deformed to seal perfectly between the plungers and the inner cylindrical surface of the high pressure chamber. Apparatus and Method to Determine $B_{0}$

Since leakage was observed at the lower pressures, it was not possible to obtain a rellable value of the bulk modulus at zero pressure $\left(B_{0}\right)$. Therefore a new apparatus was built to measure $B_{0}$. It consisted of a closed volume with very thick steel walls and a pressure transducer connected to it.

The volume was then completely filled with the test lubricant and sealed.

A temperature regulation system and a heating coll around the steel cylinder made it possible to keep the temperature and the pressure due to the thermal expansion of the 011 at predetermined values. The density of the 011 in the steel cylinder was

$$
\rho=\frac{m}{v}
$$

where $m$ was the mass and $v$ was the volume of the lubricant.

The density change due to a temperature change was

$$
\begin{gathered}
\frac{\partial \rho}{\partial t}=-\frac{m}{v^{2}} \frac{\partial v}{\partial t}=-\frac{\rho^{2}}{m} \frac{\partial v}{\partial t} \\
\frac{\partial v}{\partial t}=-\frac{m}{\rho^{2}} \frac{\partial \rho}{\partial t} \\
\frac{1}{v} \frac{\partial v}{\partial t}=-\frac{1}{\rho} \frac{\partial \rho}{\partial t}
\end{gathered}
$$

The relative increase of the steel cavity volume caused by the temperature increase was $3 \alpha \Delta t$ where $\alpha=11 \times 10^{-6}{ }^{\circ} \mathrm{C}^{-1}$ was the coeffictent of thermal expansion for the steel. 
A temperature increase of $\Delta t$, created a compression of the lubricant determined by the thermal expansion of the 011 minus the thermal expansion of the container minus the elastic increase of the container volume.

The thermal expansion of the lubricant due to the temperature increase was $\partial v / \partial t \cdot \Delta t$ and the thermal expansion of a unit volume of the lubricant was $(\partial v / \partial t) / v \cdot \Delta t$. The thermal expansion of the unit volume of the steel container was $3 \alpha v \Delta t / v=3 \alpha \Delta t$. The elastic volume increase of the steel container due to a pressure increase $\Delta p$ was $\Delta v / \Delta p \cdot \Delta p$ and the relative elastic volume increase of the container was $(1 / v) \cdot(\Delta v / \Delta p) \Delta p$. The compression of the lubricant was $(-\partial v / \partial p) \cdot \Delta p$ and the relative compression of the lubricant caused by the pressure increase $\Delta P$ was $(1 / v)(-\partial v / \partial p) \cdot \Delta p$.

$$
\begin{gathered}
\left(\frac{1}{v} \frac{\partial v}{\partial p}-3 \alpha\right) \Delta t-\frac{1}{v} \frac{\Delta v}{\Delta p} \cdot \Delta p=-\frac{1}{v} \frac{\partial v}{\partial p} \cdot \Delta p \\
\frac{1}{v} \frac{\partial v}{\partial p}=\frac{1}{v} \cdot \frac{\Delta v}{\Delta p}+\left(3 \alpha-\frac{1}{v} \frac{\partial v}{\partial t}\right) \frac{\Delta t}{\Delta p}
\end{gathered}
$$

or if Eq. (4) is used

$$
\frac{1}{B_{0}}=\frac{1}{v} \frac{\partial v}{\partial p}=\frac{1}{v} \frac{\Delta v}{\Delta p}+\left(3 \alpha+\frac{1}{\rho} \frac{\partial \rho}{\partial t}\right) \frac{\Delta t}{\Delta p}
$$

For the apparatus $(1 / v)(\Delta v / \Delta t)=0.015 \mathrm{GPa}^{-1}$ and $3 \alpha=33 \times 10^{-6}{ }^{\circ} \mathrm{C}^{-1}$.

For the different fluids the values measured at $20^{\circ} \mathrm{C}$ are given in Table I. The values of $\rho$ and $\partial \rho / \partial t$ were measured using a precision scale and calibrated volumes.

\section{Isothermal Volume Change of Lubricants with Pressure}

Vinet, Ferrante, Smith, and Rose ( 3 ) calculated the pressure as function of compression for ionic, metallic, covalent, and rare gas solids. Their equation of state gave the pressure

$$
p=\frac{3 B_{0}}{x^{2}}(1-x) \exp (n(1-x))
$$


and the bulk modulus

$$
B=\frac{B_{0}}{x^{2}}\left[2+(n-1) x-n x^{2}\right] \exp (n(1-x))
$$

as a function of the relative compression $x=\left(v / v_{0}\right)^{1 / 3}$

Here $B_{0}$ was the bulk modulus at zero pressure and

$$
n=\frac{3}{2}\left(\left(\frac{\partial B_{0}}{\partial p}\right)_{p=0}-1\right)
$$

was a function of the pressure derivative of the bulk modulus at zero pressure. These equations are valid for solids at isothermal conditions without phase change.

As the interatomic forces are similar in solids and liquids in compression, the equation of state for solids was applied as an approximation for the equation of state for liquid lubricants. If the lubricants behave in the same way as solids, the experimental points will fit the pressure deformation curve given by Eq. (8).

Lubricant molecules are normally large and complex and have different types of bondings. This is why eventually $B_{0}$ and $n$ could vary during the compression. The lubricants tested were known to convert from liquid to solid behavior within the pressure range tested. As the pressure range for the test apparatuses described earlier did not overlap, the connection between low pressure and high pressure behavior was done using curve fit techniques. The pressure and bulk modulus equations were assumed to be applicable to lubricants and the constants in the pressure equation was determined by curve fitting of the measured data.

\section{Compression Through the Solidification Boundary}

For the liquid state the Eqs. (8) and (9) were used up to the solidification pressure. In the solid state the same types of equations were used, but the values of $n, B_{0}$, and $x$ were changed. 


$$
P=\frac{3 B_{O S}}{x_{s s}^{2}}\left(1-x_{s s}\right) \exp \left(n_{s}\left(1-x_{s s}\right)\right)
$$

Here. $B_{\text {os }}$ was the bulk modulus for the solid state at zero pressure. It could not be directiy measured, but it was calculated using the equation

$$
B=\frac{B_{o s}}{x_{s s}^{2}}\left[2+\left(n_{s}-1\right) x_{s s}-n_{s} x_{s s}^{2}\right] \exp \left(n_{s}\left(1-x_{s s}\right)\right)
$$

and the assumption that the bulk modulus was a continuous function of pressure, which means that $B$ for the solid state and $B$ for the liquid state at the solidification pressure was the same. At the solidification pressure $B=B_{S}, P=p_{s}$, and $x_{s S}=x_{501}$

$$
p_{s}=\frac{3 B_{O S}}{x_{s 01}^{2}}\left(1-x_{s 01}\right) \exp \left(n_{s}\left(1-x_{501}\right)\right)
$$

The pressure in the solidified state can be written as

$$
\begin{gathered}
p=\frac{3\left(1-x_{s s}\right)}{x_{s s}^{2}} \exp \left(n_{s}\left(1-x_{s s}\right)\right) \cdot \frac{p_{s} x_{s 01}^{2}}{3\left(1-x_{s 01}\right) \exp \left(n_{s}\left(1-x_{s 01}\right)\right)} \\
\frac{p}{p_{s}}=\frac{\left(1-x_{o s} \cdot x_{s 01}\right)}{x_{o s}^{2}\left(1-x_{s 01}\right)} \exp \left(n_{s} x_{s 01}\left(1-x_{0 s}\right)\right)
\end{gathered}
$$

where $x_{0 s}=\left(v / v_{s o l}\right)^{1 / 3}$ was the relative volume calculated from the solidification volume raised to the power $1 / 3$.

$x_{\text {sol }}$ was the relative volume at the solidification pressure raised to the power $1 / 3$ assuming solid type behavior all the way down to zero pressure.

$$
x_{s S}=x_{0 S} \cdot x_{s 01}
$$

Curvefitting the experimental points gave $x_{\text {sol }}$ and $n_{s}$.

Analytical Solution for $x_{\text {sol }}$

It is possible to solve for $x_{s o l}$ if $B_{0}, n_{L}, n_{S}, B_{S}$, and $p_{S}$ are known. The equations for the pressure as a function of relative volume 
change are Eq. (8) for pressures up to the solidification pressure $P_{s}$ and Eq. (15) for pressures above $p_{5}$.

$x_{\text {sol }}$ can be solved for by using the fact that the bulk modulus is the same at the solidification pressure for both the liquid and solid state.

$x_{\text {sol }}$ is then a function of the solidification pressure $p_{s}$, the bulk modulus $B_{s}$, and the parameter $n_{s}$ for the solid state.

$$
\begin{aligned}
B_{S}=\frac{B_{0}}{x^{2}}\left[2+\left(n_{L}-1\right) x-n_{L} x^{2}\right] \exp \left(n_{L}(1-x)\right) \\
=\frac{B_{0 S}}{x_{S O 1}^{2}}\left[2+\left(n_{S}-1\right) x_{S 01}-n_{S} x_{S 01}^{2}\right] \exp \left(n_{S}\left(1-x_{S 01}\right)\right.
\end{aligned}
$$

But from Eq. (13)

$$
\begin{gathered}
\frac{B_{0 S} \exp \left(n_{s}\left(1-x_{s 01}\right)\right)}{x_{s 01}^{2}}=\frac{p_{S}}{3\left(1-x_{s 01}\right)} \\
B_{S}=\frac{B_{0}}{x^{2}}\left[2+\left(n_{L}-1\right) x-n_{L} x^{2}\right] \exp \left(n_{L}(1-x)\right) \\
=\frac{p_{s}}{3\left(1-x_{s 01}\right)}\left[2+\left(n_{s}-1\right) x_{s 01}-n_{s} x_{s 01}^{2}\right]=\frac{p_{s}}{3}\left[\frac{1}{1-x_{s 01}}+1+n_{s} x_{s 01}\right] \\
x_{s 01}=\frac{1}{2}\left(\frac{3 B_{s}}{n_{s} p_{s}}+1-\frac{1}{n_{S}}\right)-\sqrt{\frac{1}{4}\left(\frac{3 B_{s}}{n_{s} p_{s}}+1-\frac{1}{n_{S}}\right)^{2}-\left(\frac{3 B}{p_{s}}-2\right)}
\end{gathered}
$$

If $n_{s}=0$, as the experimental measurements suggest.

$$
B_{s}=\frac{p_{s}}{3}\left[\frac{1}{1-x_{s 01}}+1\right]
$$

or

$$
x_{s 01}=1-\frac{1}{\frac{3 B_{s}}{p_{s}}-1}
$$


and

$$
\frac{3 B_{0 S}}{p_{S}}=\frac{x_{s 01}^{2}}{1-x_{501}}
$$

$x_{\text {sol }}$ can be used to determine the temperature influence on the solidification pressure, as will be shown at the end of this paper. Numerical Calculations of $B_{0}$ and $\eta_{L}$

In the equations for $p$ and $B$ the values of $x$ and $n$ are not known. The compression of the fluid is only known relative to the volume at the initial pressure $0.4225 \mathrm{GPa}$. The equation for $\mathrm{p}$ will contain this unknown compression.

If the volume at zero pressure is $v_{0}$ and the volume at the starting pressure is $v_{s}$ the equation for the liquid state pressure is the same as Eq. (8) where $x$ is now given as

$$
x=\left(\frac{v}{v_{0}}\right)^{1 / 3}=\left(\frac{v}{v_{s}} \cdot \frac{v_{s}}{v_{0}}\right)^{1 / 3}=\left(\frac{v}{v_{s}}\right)^{1 / 3}\left(\frac{v_{s}}{v_{0}}\right)^{1 / 3}=\left(\frac{v}{v_{s}}\right)^{1 / 3} x_{s}
$$

$v / v_{s}$ is the relative volume calculated from the starting pressure

$$
x=\left(\frac{v}{v_{s}}\right)^{1 / 3} x_{s}=x_{0} x_{s}
$$

Using this expression for the relative volume, the pressure, and bulk modulus equations will be

$$
\begin{gathered}
p=\frac{3 B_{0}}{x_{0}^{2} x_{S}^{2}}\left(1-x_{0} x_{s}\right) \exp \left(n_{L}\left(1-x_{0} x_{s}\right)\right) \\
B=B_{0}\left[\frac{2}{x_{0}^{2} x_{S}^{2}}+\frac{n_{L}-1}{x_{0} x_{S}}-n_{L}\right] \exp \left(n_{L}\left(1-x_{0} x_{S}\right)\right)
\end{gathered}
$$


Here only the two values of $x_{s}$ and $n_{L}$ are unknown. They can be solved for by least squares techniques using the measured values of $p$ and $x_{0}$. Results From Curvefitting of the Experimental Meaurements

As the values of $B_{0}$ and $n$ are different in the liquid and solid states for the lubricants, it is possible to find the solidification pressure for a lubricant using curvefitting techniques. The solidification pressures found in this way, just by observing the change in curvature for the pressurevolume curve, are compared to the solidification pressures found by measuring the shear strength of the lubricants in Table II. The two completely different methods to determine the solidification pressures give a good agreement. The mean absolute difference being about 5 percent and the maximum difference being 8.9 percent. The solidification pressure in the curve fitting experiments has been assumed to coincide with one of the measured pressures. The pressure step from one experimental point to the next at the solidification pressure could be as much as 15 percent though, explaining most of the scatter. In Table II are also given the measured or calculated parameter values for the different lubricants. $v_{s t a r t} / v_{0}=x_{s}^{3}$ is the relative volume of the lubricant at the start pressure, $0.4225 \mathrm{GPa}$, of the experiment. $n_{L}$ is the slope parameter describing the slope of the curves in Fig. 3. The parameter $n_{s}$ for the solid state of all tested lubricants was found to be zero. $v_{\text {sol }} / v_{\text {start }}$ is the volume at the solidification pressure divided by the volume at the pressure $0.4225 \mathrm{GPa}$. If the stiffness of the 011 was the same as at the solidification pressure and the parameter $n_{s}=0$ from zero pressure to the solidification pressure, the fictitious relative volume at the solidification pressure should be $v_{\text {sol }} / v_{\text {sol, }} 0^{\circ}$ This relative volume, also given in Table II, will be used in the calculations of the change of solidification pressure with temperature. 
In Fig. 2 the compression as a function of the pressure is shown for six different fluids. The solid lines are the theoretical curves from Ref. 3 fitted to the experimental points shown in the figures. The fits between the theoretical curves and the experimental points are remarkably good. In Fig. 3 the natural logarithm of the nondimensional bulk modulus is shown as a function of the compression parameter $x=\left(v / v_{0}\right)^{1 / 3}$. The theoretical solid lines and the experimental points are shown for the six fluids. The parameter $n$ in Eq. (8) is shown in this type of plot as the slope of the curves. It is clearly visible from all six diagrams in Fig. 3 that the parameter $n_{s}$ for the solid state is zero.

The Change of Solidification Pressure Caused by a Temperature Change

As earlier mentioned Vinet, Ferrante, Smith, and Rose ( $\underline{3}$ ) published equations for the pressure as a function of compression and the bulk modulus as a function of pressure. These equations were valid for isothermal conditions without phase changes. Experiments with lubricating oils showed that the bulk modulus at low pressures is almost independent of the temperature. The total pressure and compression of an 011 needed to convert it from a liquid to a solid state increases with increasing temperature. The Idea behind this part of the paper is that the absolute density (or volume) determines the switch from liquid to solid state for lubricants. This means that the thermal expansion due to a temperature increase has to be compensated by a pressure increase which increases the density to the value needed for solidification.

If the volume coefficlent of thermal expansion for the fluid is $\delta^{\circ} \mathrm{C}^{-1}$, the change in solidification pressure with temperature is given by the thermal expanston

$$
v \delta \cdot \Delta t=3 \Delta x v
$$

where 


$$
\begin{gathered}
\frac{v+\Delta v}{v}=x^{3}=(1+\Delta x)^{3}=1+3 \Delta x+3 \Delta x^{2}+\Delta x^{3} \\
\frac{\Delta v}{v} \approx 3 \Delta x \text { since } \Delta x \ll 1
\end{gathered}
$$

where $x$ is the parameter in the pressure equation. The pressure as a function of $B_{0}, x$, and $\eta$ is given by Eq. (8).

The experimental measurements in Fig. 3 show that the parameter value $n$ in the solid state is $n_{s}=0$. This indicates a simple method to calculate the change in solidification pressure caused by a change in temperature.

At the solidification pressure for a lubricant with the temperature $t_{1}$ Eq. (8) can be rewritten as

$$
\ln \left[\frac{p_{s 1} \cdot x_{s 01}^{2}}{3\left(1-x_{s 01}\right) B_{o s}}\right]=\left(1-x_{s 01}\right) n_{s}=0
$$

where $x_{\text {sol }}^{3}=v_{\text {sol }} / v_{\text {sol, }}$ is given in Table II.

If the lubricant then is further compressed to the pressure $p_{52}$ and. heated to the temperature $t_{2}$, giving the thermal expansion $3 \Delta x=\delta\left(t_{2}-t_{1}\right)$ from Eq. (28), then Eq. (8) will give

$$
\ln \left[\frac{p_{s 2} \cdot\left(x_{s 01}-\Delta x\right)^{2}}{3\left(1-x_{s 01}+\Delta x\right) B_{0 s}}\right]=\left(1-x_{s 01}+\Delta x\right)_{n_{s}}=0
$$

The solidification pressure at temperature $t_{2}$ divided by the solidification pressure at temperature $t_{1}$ can then be solved for from Eqs. (31) and (32).

$$
\frac{p_{s 2}}{p_{s 1}}=\left(\frac{x_{s 01}}{x_{s 01}-\Delta x}\right)^{2} \cdot \frac{1-x_{s 01}+\Delta x}{1-x_{s 01}}
$$

Example

For a typical lubricating ofl $n_{L}$ is of the order 10 to 30 and $n_{S} \approx 0$. The compression needed to solidify it is $\Delta v / v_{0}=0.2 \pm 0.05$ and if the $0 i 1$ had had the same stiffness as in the solidified state the compression needed 
to reach the solidification pressure would have been $\left(\Delta v / v_{0}\right)_{s 01}=0.040-$ 0.084 . The thermal expansion caused by a temperature increase of $20^{\circ} \mathrm{C}$ (from 20 to $\left.40^{\circ} \mathrm{C}\right)$ is from Table I.

$$
\Delta x=7.25 \times 10^{-4} \times 20 / 3=0.00483
$$

and from Table II $x_{\text {sol }}{ }^{3}=0.9359, x_{\text {sol }}=0.978$ for the lubricant ditridecyladipate 26 cSt.

This gives

$$
\begin{aligned}
& \frac{p_{s 1} x_{s 01}}{1-x_{s 01}}=\frac{p_{s 2}\left(x_{s 01}-\Delta x\right)^{2}}{1-x_{s 01}+\Delta x} \\
& \frac{p_{s 2}}{p_{s 1}}=\left(\frac{x_{s 01}}{x_{s 01}-\Delta x}\right)^{2} \cdot \frac{1-x_{s 01}+\Delta_{x}}{1-x_{s 01}}=\left(\frac{0.978}{0.978-0.00483}\right)^{2} \cdot \frac{0.02683}{0.022} \\
& \frac{p_{s 2}}{p_{s 1}}=1.232
\end{aligned}
$$

The compression experiments gave for the two temperatures 40 and $20^{\circ} \mathrm{C}$, $p_{s 2} / p_{s 1}=1.95 / 1.58=1.234$.

For a 450 cst polyalphaolefine lubricant $x_{51}=0.971, \Delta x=0.003937$ for $\Delta t=20{ }^{\circ} \mathrm{C}$ gave $p_{s 2} / p_{s 1}=1.147$ and the compression experiments gave $p_{s 2} / p_{s 1}=2.06 / 1.80=1.144$.

For a naphthenic base distillate with a very low solidification pressure $\left(p_{s}=0.67 \mathrm{GPa}\right.$ at $\left.20^{\circ} \mathrm{C}\right)$ the constants from the numerical curve fitting was $x_{\text {sol }}=0.9865 \Delta x=0.00896$ for a temperature change of $40^{\circ} \mathrm{C}$.

$$
\frac{p_{s 2}}{p_{s 1}}=\left(\frac{0.9865}{0.97754}\right)^{2} \cdot \frac{0.02246}{0.01350}=1.694
$$

and the experiments gave $p_{s 2} / p_{s 1}=1.13 / 0.67=1.687$.

These values show a remarkably good agreement between theory and experiments. 


\section{CONCLUSIONS}

Two pressure chambers, for measurement of compressibility and bulk modulus for liquids from zero to $2.2 \mathrm{GPa}$ pressure, are described. The experimentally measured compressions are then compared to values given by an isothermal equation of state for solids in compression. The equation describes the pressure and bulk modulus for different types of lubricants with a very high accuracy up to the pressure limit of the high pressure chamber used (2.2 GPa).

The influence of temperature on static solidification pressure was found to be a simple function of the thermal expansion of the fluid.

\section{ACKNOWLEDGMENT}

P. Vinet would Tike to thank the French "Ministere des relations exteriures" for providing him a grant. B. Jacobson would like to thank Jacob Wallenberg's foundation and NASA Lewis Research Center for financial support of the project. The authors are also indebted to Osten Uusitalo and Sten Ivar Bergstrom for experimental support. 


\section{REFERENCES}

1. Hoglund, E., and Jacobson, B., "Experimental Investigation of the Shear Strength of Lubricants Subjected to High Pressure and Temperature," ASME Paper 85-Trib-34, 1985.

2. Hamrock, B.J., Jacobson, B.0., and Bergstrom, S.-I., 1985, "Measurement of the Density of Base fluids at Pressures to $2.2 \mathrm{GPa}$ " NASA TM-87114, 1986.

3. Vinet, P., Ferrante, J., Smith, J.R., and Rose, J.H., "A Universal

Equation of State for Solids," Proposed Journal letter, prepared for Physical Review letters, 1985. 
TABLE I. - EXPER IMENTAL RESULTS

\begin{tabular}{|c|c|c|c|c|l|}
\hline $\begin{array}{c}\text { Lubricant, } \\
n r\end{array}$ & $\rho$ & $\frac{\partial \rho}{\partial t}$ & $\frac{\Delta t}{\Delta p}$ & $\frac{1}{v} \frac{\partial v}{\partial p}$ & $B_{o}$ \\
\cline { 2 - 6 } & $\mathrm{kg} / \mathrm{m}^{3}$ & $\mathrm{~kg} / \mathrm{m}^{3}{ }^{\circ} \mathrm{C}$ & ${ }^{\circ} \mathrm{C} / \mathrm{GPa}$ & $\mathrm{GPa}^{-1}$ & $\mathrm{GPa}$ \\
\hline 1 & 846 & -0.591 & 1043 & -0.679 & 1.473 \\
2 & 910 & -.660 & 910 & -.615 & 1.626 \\
3 & 1005 & -.726 & 995 & -.672 & 1.488 \\
4 & 1004 & -.716 & 910 & -.604 & 1.656 \\
5 & 931 & -.626 & 940 & -.586 & 1.706 \\
6 & 892 & -.629 & 910 & -.597 & 1.675 \\
\hline
\end{tabular}

TABLE II. - MEASURED AND CALCULATED VALUES

\begin{tabular}{|c|c|c|c|c|c|c|c|c|}
\hline $\begin{array}{c}0 \mathrm{il}, \\
\mathrm{nr}\end{array}$ & $\begin{array}{c}\text { Solidification } \\
\text { pressure from } \\
\text { curve fit, } \\
\text { GPa }\end{array}$ & $\begin{array}{c}\text { Solidification } \\
\text { pressure from } \\
\text { shear strength } \\
\text { measurement, } \\
\text { GPa }\end{array}$ & $\begin{array}{c}\text { Bulk } \\
\text { modulus } \\
\text { at zero } \\
\text { pres- } \\
\text { sure B }{ }_{0} \text {, } \\
\text { GPa }\end{array}$ & $\begin{array}{c}v_{\text {start }} \\
v_{0} \\
x_{s}^{3}\end{array}$ & $\frac{3}{2}\left(\left(\frac{\partial B}{\partial p_{0}}\right)-1\right)$ & $\frac{v_{\text {sol }}}{v_{\text {start }}}$ & $\begin{array}{l}\frac{v_{\text {sol }}}{v_{\text {sol }, 0}} \\
x_{\text {sol }} 3\end{array}$ & $\begin{array}{l}\text { Lubricant } \\
\text { type }\end{array}$ \\
\hline 1 & 1.650 & 1.682 & 1.473 & 0.8654 & 13.65 & 0.8718 & 0.9161 & $\begin{array}{l}\text { Polyalphaole- } \\
\text { fine } 450 \text { est }\end{array}$ \\
\hline 2 & 1.449 & 1.561 & 1.626 & .8697 & 13.47 & .8899 & .9359 & $\begin{array}{l}\text { Ditridecylade- } \\
\text { pate } 26 \text { cst }\end{array}$ \\
\hline 3 & 0.995 & 1.092 & 1.488 & .8736 & 14.84 & .9252 & .9581 & $\begin{array}{l}\text { Polypropylene- } \\
\text { glycole } 175 \text { cst }\end{array}$ \\
\hline 4 & 1.124 & 1.213 & 1.656 & .8734 & 13.71 & .9247 & .9525 & $\begin{array}{l}\text { Polypropylene- } \\
\text { giycole } 80 \text { cst }\end{array}$ \\
\hline 5 & .676 & 0.706 & 1.706 & .9014 & 25.27 & .9759 & .9600 & $\begin{array}{l}\text { Naphthenic base } \\
\text { distillate } 26 \text { cst }\end{array}$ \\
\hline 6 & .834 & .839 & 1.675 & .8945 & 20.93 & .9564 & .9501 & $\begin{array}{l}\text { Naphthenic base } \\
\text { raffinate } 23 \text { cst }\end{array}$ \\
\hline
\end{tabular}




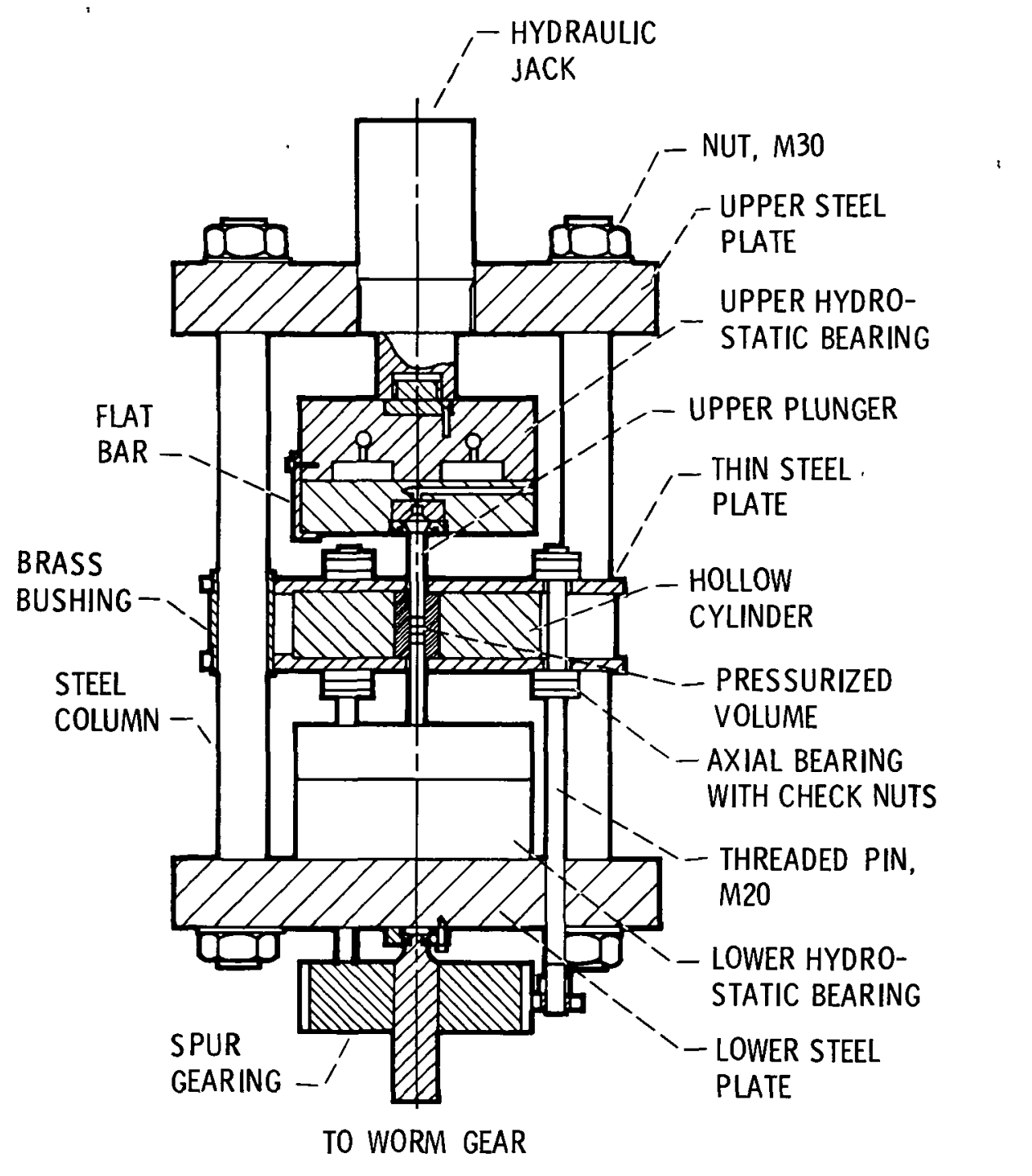

Figure 1. - Main parts of experimental apparatus. 
$\left(1-x^{3}\right)$ vs $P$

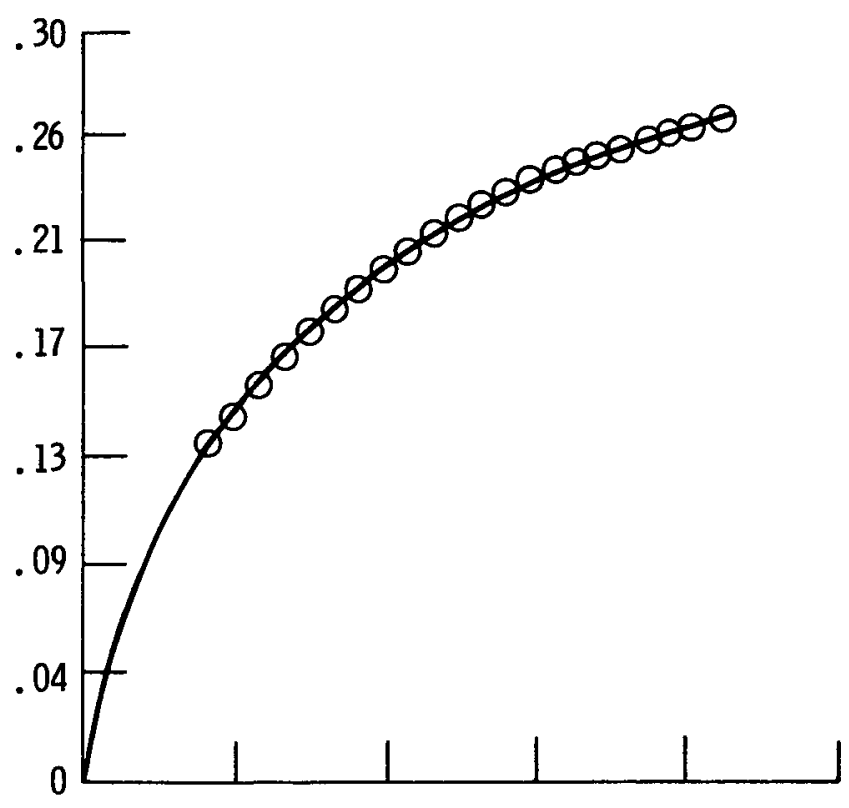

(a) Polyalphaolefine $450 \mathrm{cSt}$.
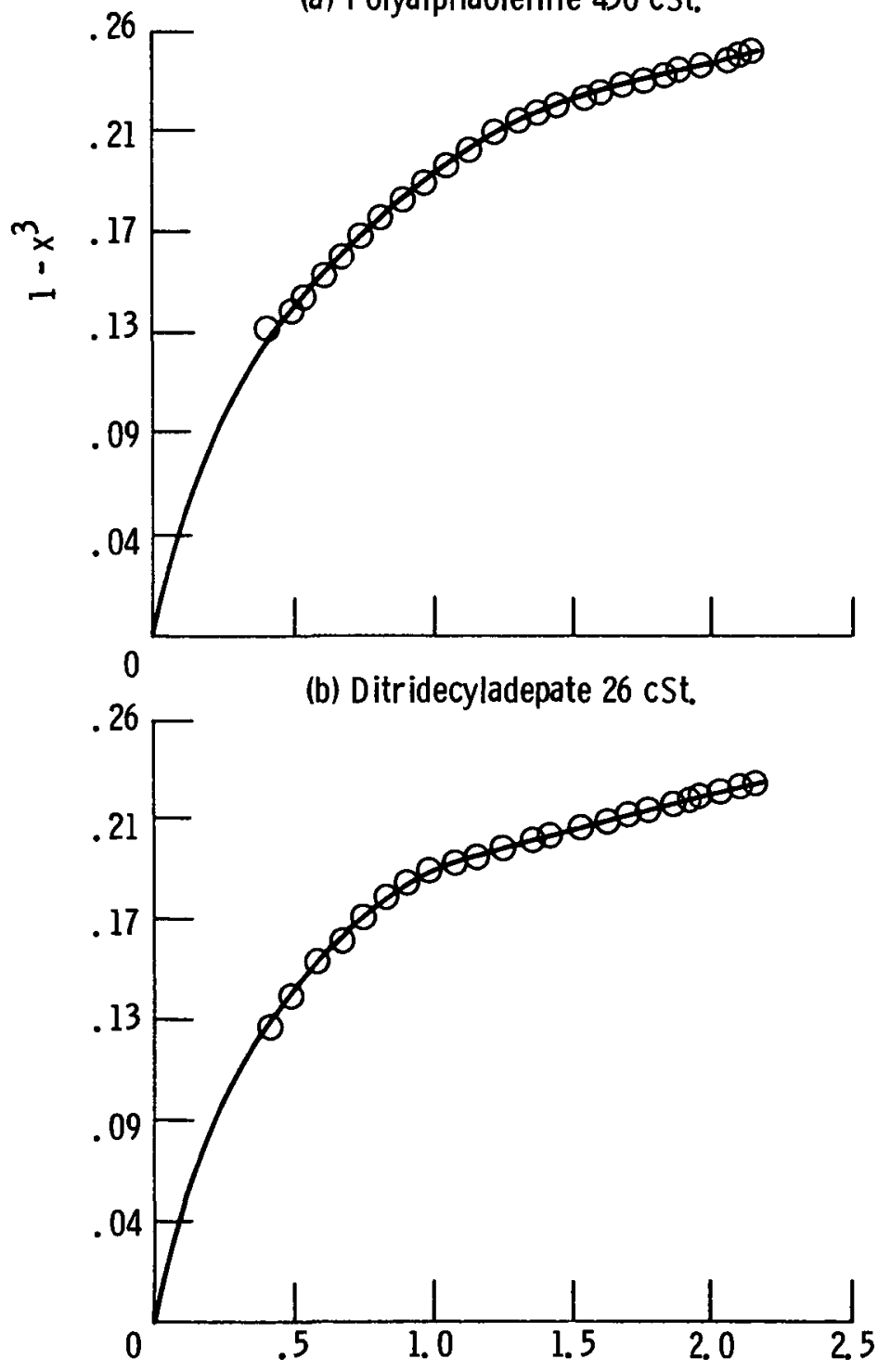

(c) Polypropyleneglycole 175 cSt.

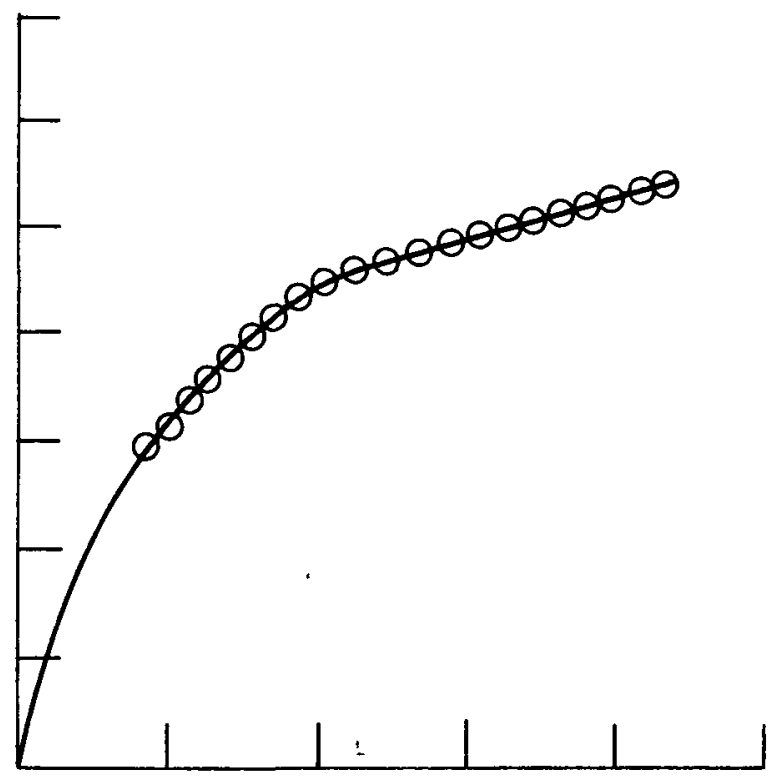

(d) Polypropyleneglycole $80 \mathrm{cSt}$.

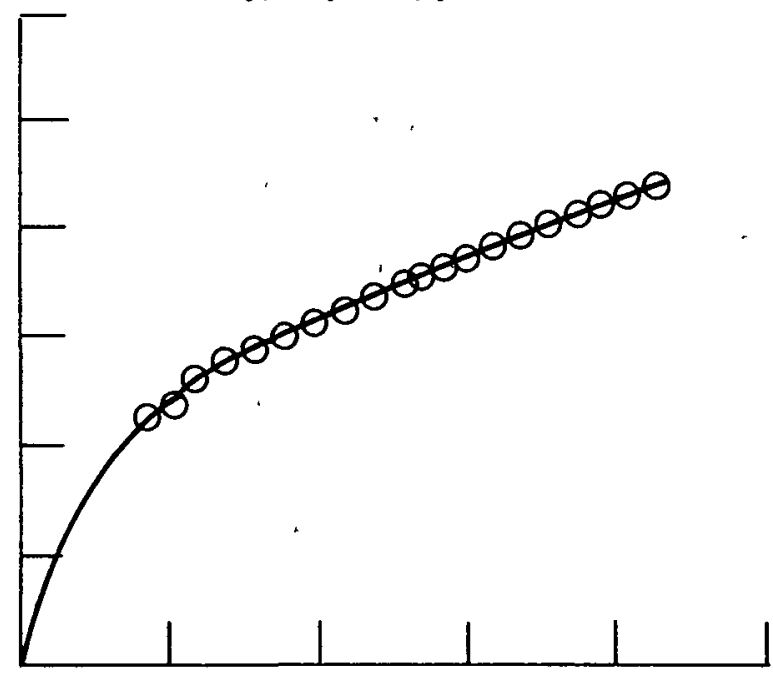

(e) Naphthenic base distillate 26 cSt.

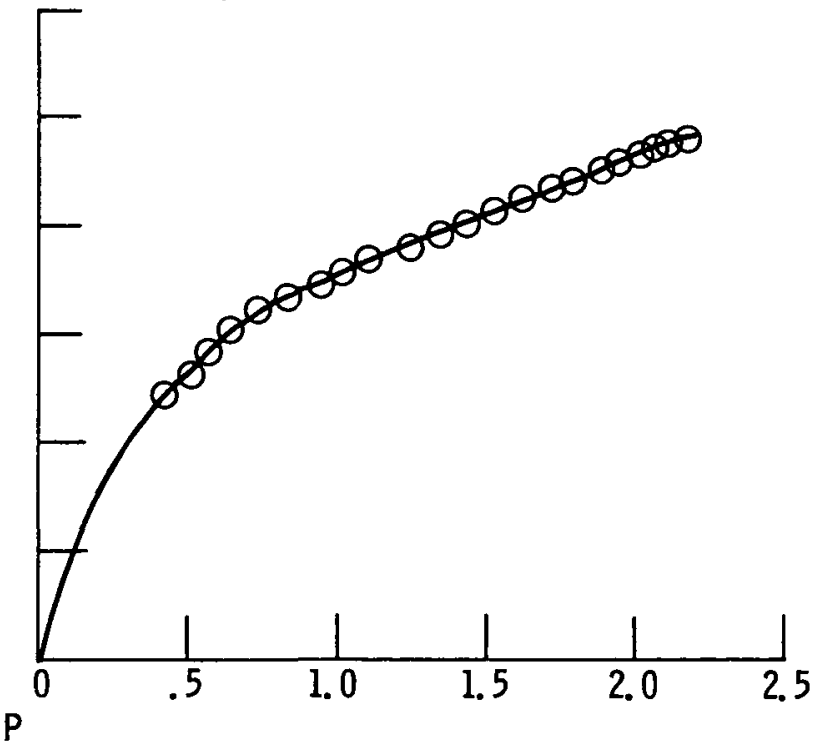

(f) Naphthenic base raffinate 23 cSt.

Figure 2 - Theoretical compression curves and experimental points for the six lubricants tested. 
$\ln \left[p x^{3} 13 B_{0}(1-x)\right]$ vS $(\vec{l}-x)$

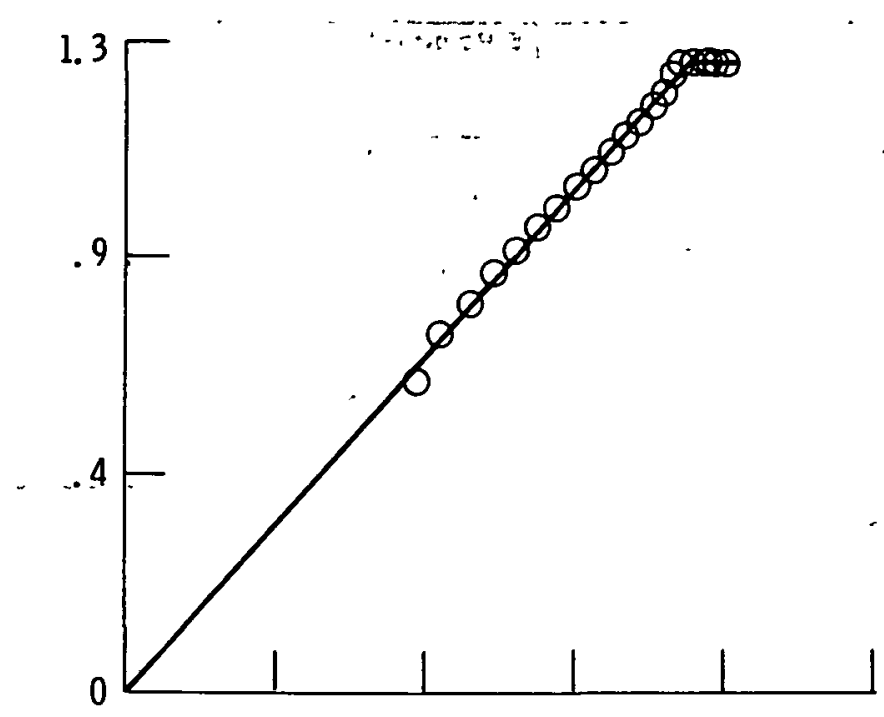

(a) Polyalphaolefine $450 \mathrm{cSt}$.

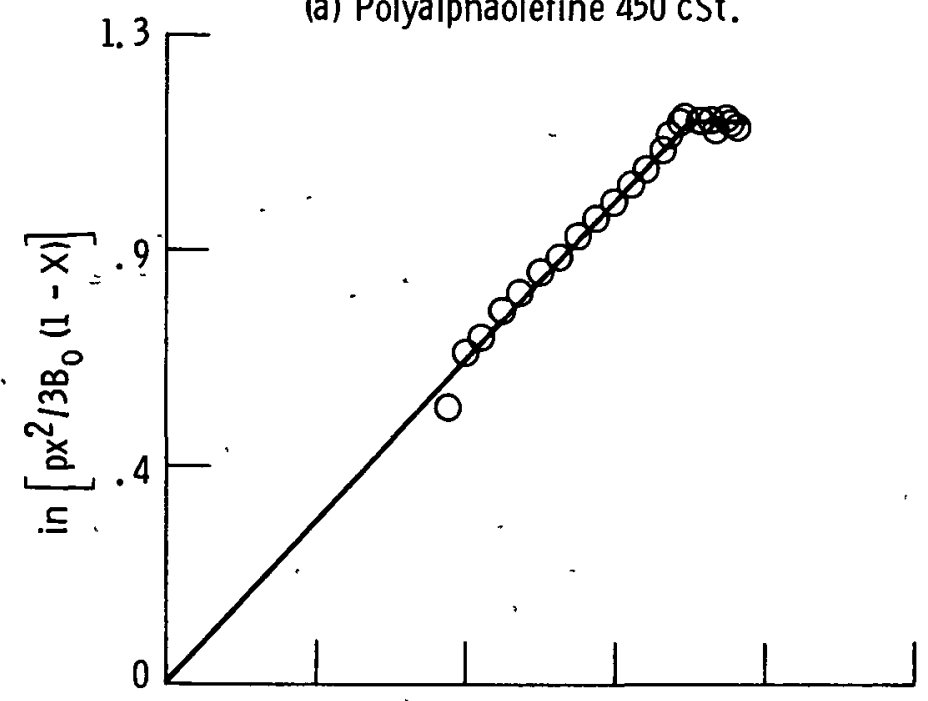

(b) Ditridecyladepate 26 cSt.

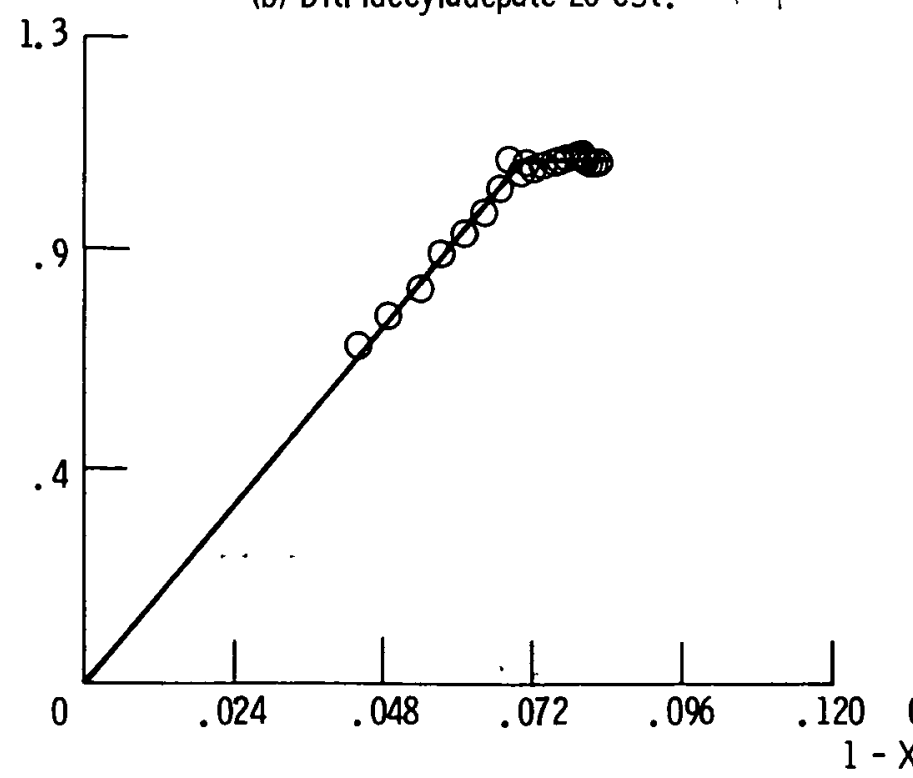

(c) Polypropyleneglycole 175 cSt.

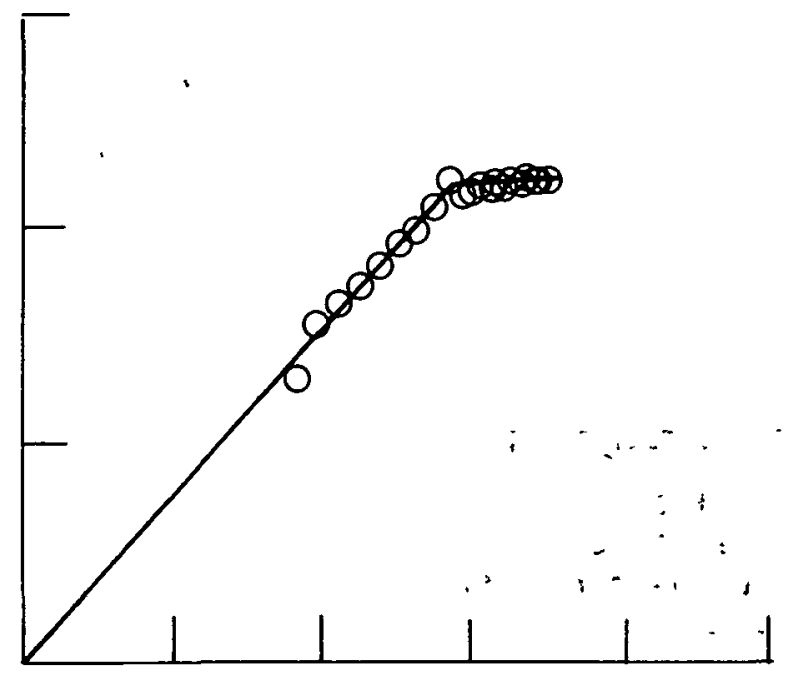

(d) Polypropyleneglycole 80 cSt.

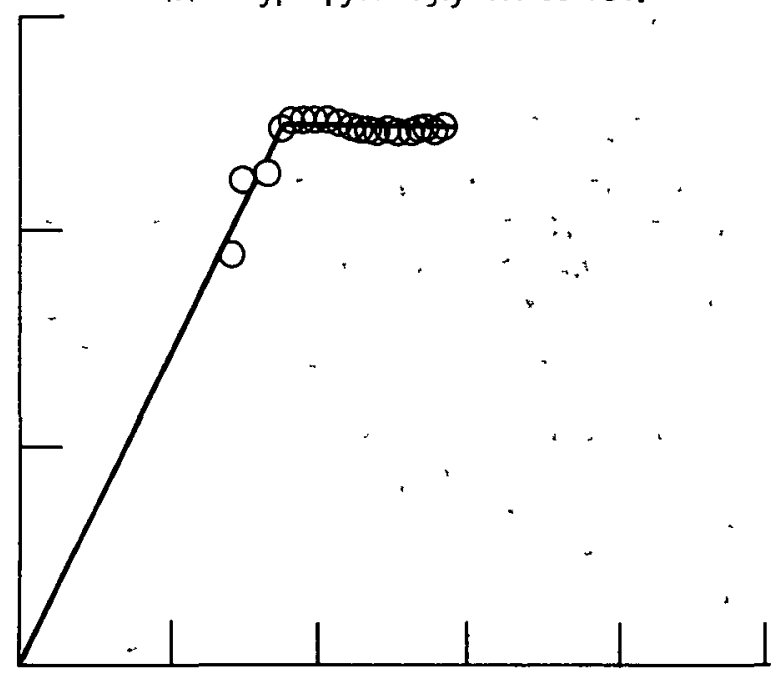

(e) Naphthenic base distillate 26 cSt.

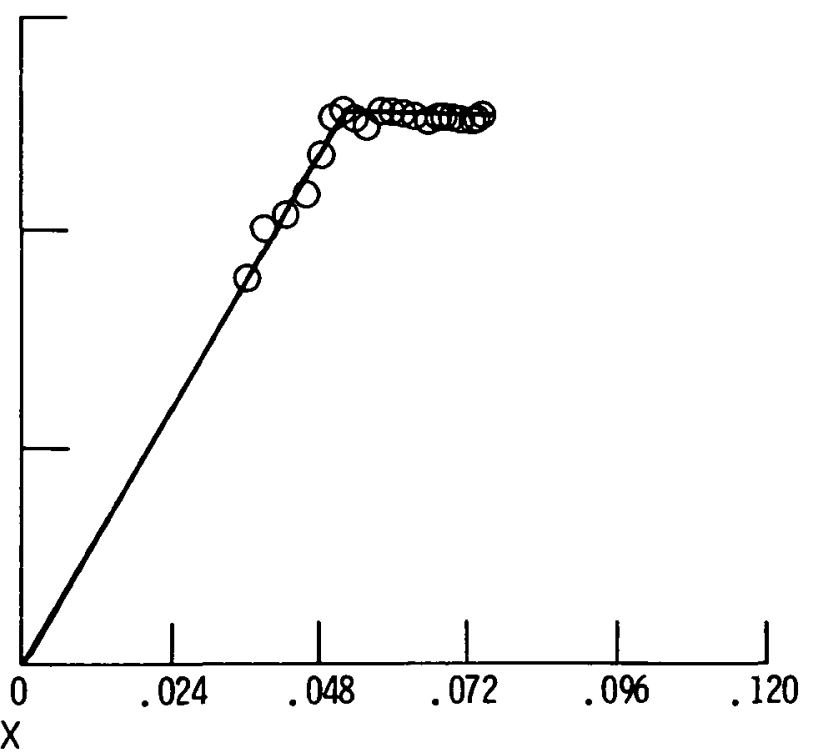

(f) Naphthen ic base raffinate $23 \mathrm{cSt}$.

Figure 3. - Theoretical curves and experimental points showing $\ln \left(\mathrm{px}^{2} / 3 \mathrm{~B}_{0}(1-\mathrm{x})\right)$ as a function of $1-x$ for the six lubricants. 


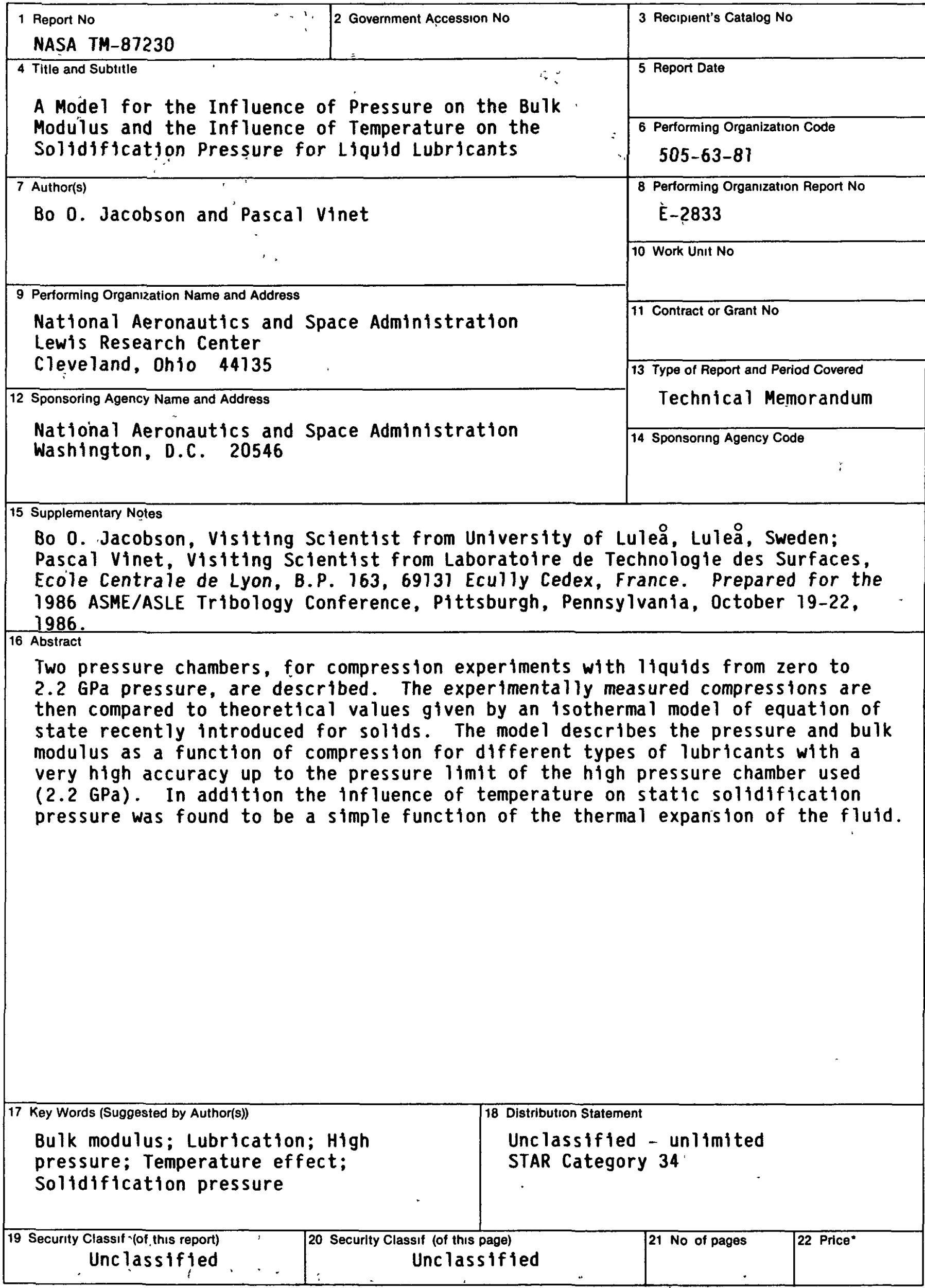

"For sale by the Natıonal Technical Informatıon Service, Springfıeld, Virgınıa 22161. 